\title{
How big pharma and regulators fail clinicians
}

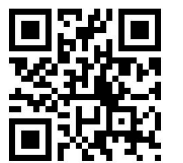

Generalists daily make poor evidence-based decisions because regulatory and ethics committees fail them and drug companies habitually misrepresent products. The pervasiveness of this perversion - at least overseas - is best illustrated by the equivalent of R131.4 billion in healthcare fraud settlements made by pharmaceutical corporates in the USA over the last 10 years, with the most recent individual company fines breaking all records.

Professor Keymanthri Moodley, head of the Centre for Medical Ethics and Law in the Faculty of Health Sciences at Stellenbosch University, revealed this while discussing challenges in the ethics of medical generalism at the 16th National Family Practitioners conference in Observatory, Cape Town, on 11 May this year. She said that one of the significant challenges in generalism was the growing base of easily accessible scientific data, of which a significant proportion is unreliable. The ability to critique this data was vital to evidence-based medicine, and doctors/ clinicians faced a major dilemma in sifting out what was falsely presented to them. Citing what she termed 'a favourite book of mine' (Bad Pharma by epidemiologist Ben Goldacre), ${ }^{[1]}$ she said that positive findings were twice as likely to be published as negative findings, which Goldacre describes as 'a cancer at the core of evidence-based medicine'. She said Goldacre outlined the myriad ways in which regulatory and research ethics committees let the profession down, while numerous studies involving routine treatments (she singled out antidepressants and statins) were deeply flawed and 'presented in a skewed direction'. Goldacre estimates that $25 \%$ of the massive global turnover of the pharmaceutical industry goes to advertising and promotion, which translates inter alia to incentives to doctors in the form of gifts, promotional meetings and conferences, overseas travel expenses (including spouses and partners), sponsored hospital grand rounds and other clinical meetings, and even holidays. 
Companies draft study protocols and trial results for lead investigators to sign off, with negative and non-supporting results buried and not published. Under such circumstances, doctors are no better than ordinary consumers, he says. Goldacre provides examples to show that the industry, profession, research ethics committees, medical journals and regulatory authorities lack vigilance in the design, conduct, analysis and interpretation of clinical studies.

Moodley said that, as a result, and in pursuit of evidence-based medicine, 'we may sometimes do more harm than good to our patients'. She said it was getting worse, citing some of the most recent billion-dollar fines paid by major pharmaceutical companies in the USA, many of them repeat offenders who seemed to write off such punitive measures as 'a mere cost of doing business'. On 2 July last year, GlaxoSmithKline (GSK) agreed to plead guilty to three criminal counts for sales of misbranded Paxil (paroxetine) and Wellbutrin (bupropion) - drugs promoted for indications for which they had not been approved by the FDA (aka off-label promotion). Under both criminal and civil charges, they paid today's equivalent of R28.3 billion to the federal government and participating states. At the time this settlement was announced, 25 major companies and 8 of the top 10 global pharmaceutical companies were under 'corporate integrity agreements', a routine part of settlements for healthcare fraud, typically requiring enhanced compliance activities within the company for 5 years, including reports to the government from an independent monitor GSK also pleaded guilty to failing to report safety data on Avandia (rosiglitazone) and violating the Food, Drug and Cosmetic Act. ${ }^{[2]}$ A year earlier, biotechnology company Amgen paid R235 million in a settlement over whistleblower allegations that they paid kickbacks to longterm care pharmacies to increase the use of an anaemia drug in nursing homes. Amgen allegedly pressured pharmacists to recommend Aransep (darbepoetin alfa) for nursing home residents who did not have anaemia associated with chronic renal failure, and distributed materials and sponsored programmes promoting this off-label use of the medication. (The company denied all allegations as part of the settlement). In December last year, Amgen settled another suit for R7.187 billion and accepted a corporate integrity agreement. A third case against them is pending. ${ }^{[3]}$

Moodley said a second major challenge faced by generalists was their relationship with specialists. GPs found themselves at the centre of a network of specialists, medical funders, radiology and pathology companies and the pharmaceutical industry. Given this web of relationships, conflict was bound to arise. However, the basic guiding principles in generalist-specialist disagreements included patient welfare and best interests, and mutual integrity and respect. She urged more experienced doctors to become aware that they acted as 'role models' to students and young doctors who 'watch us and will replicate inappropriate behaviour'. With generalism often regarded as 'the stepsister' in healthcare provision, inappropriate remarks were sometimes made by specialists with respect to generalist referral notes and generalists. She said it was vital that health resources were used 'appropriately and prudently', and referrals were one area where social relationships and specialist touting could contribute to suboptimal care. The ultimate responsibility for co-ordinating patient care lay with the referring doctor. 'Increasingly problematic' was specialists becoming the first point of contact for patients and actively encouraging patients to book appointments with them instead of via their GPs.

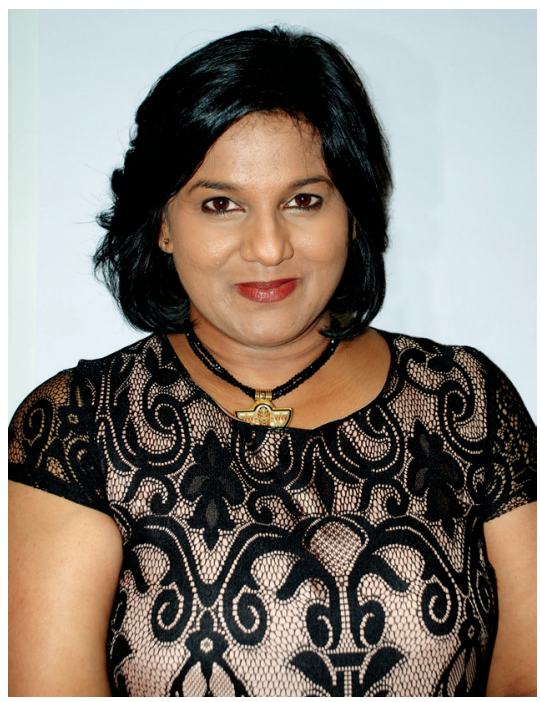

Professor Keymanthri Moodley, head of the Centre for Medical Ethics and Law in the Faculty of Health Sciences at Stellenbosch University (photo by Chris Bateman).

Another challenge for generalists was other professions taking on additional responsibilities, e.g. pharmacies that offered a wide and welcome range of screening tests but where pharmacists often indulged in diagnosis and therapeutics. 'I often stand at the pharmacy counter and listen to people presenting symptoms in full earshot of all present, and I am amazed at how pharmacists come up with diagnoses (and then dispense without examining patients); I have to try very hard not to intervene.' The ethos of medical generalism focused on empathy which she described as 'the intelligent use of insight into the whole setting of the patient's plight, engagement (or a commitment to active involvement in every aspect of the patient's care), an appreciation of the GP's limits (understanding and acknowledging the specialist aspect of care) and knowing when to refer a patient. Every GP also had to deal with 'end of life' issues; she emphasised the role of patient autonomy in exercising both the right to life and the right to a dignified death. Organisations across the globe, especially in Switzerland

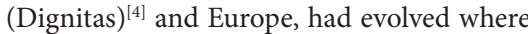
'anyone with 10000 Francs can go and deliberately choose to end their life, usually in the terminal phase of an illness'. 'End of life/suicide tourism is a reality. It's happening in a more transparent and powerful way than ever before. We're all comfortable with a patient's right to life but we need to deal with their right to end their lives when they so desire, especially in the context of terminal and debilitating illnesses,' she added.

Dignitas offers assisted suicide to any member (including foreigners) suffering from a terminal or unendurable illness who wishes to end their life and suffering. They use a lethal, fast-acting and painless barbiturate dissolved in drinking water. Each permitted use of the medication requires a Swiss doctor's prescription, an in-depth evaluation of the member's written request and medical information, and at least two face-to-face meetings with Dignitas' doctors. The member must be of sound judgement and possess a minimum level of physical mobility (sufficient to self-administer the drug).

Professor Moodley said her 'take home' messages were to critically appraise scientific evidence that guides generalist clinical care and to encourage teamwork in healthcare provision, 'especially where generalists and specialists work together in a complementary manner with mutual respect and open communication for the benefit of the patient?

\section{Chris Bateman}

chrisb@hmpg.co.za

$$
\begin{aligned}
& \text { 1. Goldacre B. Bad Pharma: How Drug Companies Mislead Doctors } \\
& \text { and Harm Patients. London: Fourth Estate, } 2012 \text {. } \\
& \text { 2. Outterson K. Punishing health care fraud - is the GSK settlement } \\
& \text { sufficient? N Engl J Med 2012;367:1082-1085. } \\
& \text { 3. FiercePharma. Amgen whistleblower went undercover for the } \\
& \text { feds. http://www.fiercepharma.com/story/amgen-whistleblower- } \\
& \text { went-undercover-feds/2012-12-20 (accessed 20 May 2013). } \\
& \text { 4. http://www.dignitas.ch/index.php?option=com_content\&view=a } \\
& \text { rticle\&id=20\&lang=en (accessed 20 May 2013). }
\end{aligned}
$$

S Afr Med J 2013;103(7):440-441

DOI:10.7196/SAMJ.7099 